\title{
A AMAZÔNIA NO(S) DISCURSO(S) DOS BOIS-BUMBÁS DE PARINTINS
}

\section{THE AMAZON IN THE DISCOURSE(S) OF THE BOI-BUMBÁS FROM PARINTINS}

\author{
Claudiana Narzetti ${ }^{1}$, Mileny Brandão ${ }^{2}$
}

\begin{abstract}
RESUMO: Neste artigo, apresentam-se resultados parciais de pesquisa em andamento acerca do(s) discurso(s) dos Bois-Bumbás de Parintins, Garantido e Caprichoso, materializado(s) nas letras de suas toadas. Especificamente, faz-se análise discursiva de um recorte do corpus da pesquisa, que consiste em sequências discursivas (versos das toadas) nas quais são empregadas as palavras-chave "floresta" "natureza", "mata", "selva", "Amazônia". A questão geral é: a acentuada rivalidade entre os dois Bois-Bumbás correlaciona-se a relações de oposição e conflito também no discurso? A questão específica é: qual o discurso deles sobre a floresta? O referencial teórico é o da AD francesa derivada dos trabalhos de Michel Pêcheux. A metodologia da pesquisa é comparativa/contrastiva, seguindo trabalhos pioneiros em AD na França (1960-70). Os resultados indicam que os referidos Bois-Bumbás não apenas sustentam o mesmo discurso sobre a Amazônia, mas também discursivizam os mesmos objetos de discurso.
\end{abstract}

PALAVRAS-CHAVE: Análise do discurso francesa; toadas de Boi-Bumbá; Amazônia

ABSTRACT: This article, presents partial results of ongoing research on the speech $(s)$ of the Boi-Bumbás from Parintins, Garantido and Caprichoso, materialized in the letters of their "toadas" (the songs played by the Bois-Bumbás). Specifically, a discursive analysis is made of a chunk of the research corpus, which consists of discursive sequences (verses of the toadas) in which the key word "forest" "nature","jungle", "Amazon" is used. The general question is: does the marked rivalry between the two Bois-Bumbás correlate to opposition and conflict relations in discourse as well? The specific question is: what is their discourse about the forest? The theoretical reference is that of French Discourse Analysis (DA) derived from the work of Michel Pêcheux. The research methodology is comparative/contrastive, following pioneering works in DA in France (1960-70). The results indicate that the aforementioned Bois-Bumbás sustain the same discourse on the Amazon.

KEY-WORDS: French discourse analysis; Boi-Bumbá songs; Amazon

\section{Introdução}

\footnotetext{
${ }^{1}$ Docente do Curso de Letras - Língua Portuguesa e do PPG em Letras e Artes, da UEA. Projeto com apoio Fundação de Amparo à Pesquisa do Estado do Amazonas (FAPEAM). 2 Mestranda do PPG em Letras e Artes da UEA. Bolsista do Programa de Amparo à Pesquisa do Estado do
Amazonas (FAPEAM). Professora de Língua Portuguesa da Secretaria Estadual de Educação do Amazonas.
} 
O presente artigo visa a descrever-interpretar, a partir da Análise do discurso francesa derivada dos trabalhos de Michel Pêcheux, o(s) discurso(s) dos Bois-Bumbás de Parintins, Garantido e Caprichoso, tal como materializado nas letras de suas toadas.

A questão principal da pesquisa mais ampla da qual este artigo apresenta resultados parciais é: a acentuada rivalidade entre os dois Bois-Bumbás correlaciona-se a relações de oposição e conflito também em seu discurso? Em caso positivo, poder-se-ia, então, afirmar que os discursos dos Bois-Bumbás provêm de formações discursivas contraditórias? Em caso negativo, poder-se-ia, por outro lado, afirmar que os discursos dos Bois-Bumbás provêm da(s) mesma(s) formação(ões) discursiva(s) e que, portanto, trata-se de um único discurso?

As respostas a essas questões são buscadas na análise de um conjunto de sequências discursivas construídas em torno de palavras-chave tais como: "floresta", "natureza", "mata", "selva", "Amazônia" e "caboclo", e, ainda, que tematizem a cidade de Parintins, o modo de vida de seu povo (costumes, religiosidade, valores) e ao brincante/torcedor dos Bois-Bumbás.

Especificamente, a descrição-interpretação proposta no presente artigo, atém-se, em função de seus objetivos, às sequências discursivas (versos das toadas) em torno das palavraschave "floresta", "selva", "natureza", "mata" e "Amazônia", coletados de toadas produzidas no período que vai de 1995 a 2015 . A partir desse recorte, é possível avançar algumas respostas acerca das questões acima elencadas.

A metodologia de análise do corpus é comparativa/contrastiva, seguindo o caminho aberto por alguns trabalhos pioneiros em Análise do discurso França nos anos 1960-70. Essa metodologia parece ser apropriada na medida em que conduz a analisar discursos em relação, e não um único discurso em si mesmo, o que poderia conduzir a conceber o discurso como homogêneo e constituído independentemente de outros.

A pesquisa, ainda que tratando especificamente do(s) discurso(s) dos Bois-Bumbás de Parintins, pode contribuir para uma descrição dos discursos em circulação sobre a Amazônia. Além disso, a pesquisa também contribui para o campo da análise do discurso de orientação materialista, com a descrição-interpretação de um discurso em particular.

$\mathrm{O}$ artigo está estruturado da seguinte maneira. Inicialmente, abordam-se algumas informações sobre o Festival Folclórico de Parintins. Em seguida, apresenta-se a fundamentação teórica da pesquisa, qual seja a Análise do discurso francesa, derivada dos trabalhos de Michel Pêcheux. Por fim, apresenta-se a análise do discurso dos Bois-Bumbás Garantido e Caprichoso a partir de sequências discursivas acima descritas, momento em que não só se descreve/interpreta o referido discurso, mas também expõem-se aspectos metodológicos da pesquisa. 


\section{Parintins e o Festival Folclórico}

Esta seção aborda suscintamente algumas informações sobre a cidade de Parintins-AM e sobre a festa do Boi-Bumbá. São informações gerais que visam a situar o leitor para que possa melhor compreender a análise a ser apresentada na última seção.

Parintins (também conhecida como Ilha Tupinambarana, pois foi habitada pelos índios Tupinambás, Maués e Sapupés) é um município do estado do Amazonas reconhecido mundialmente pelo seu Festival Folclórico que acontece todos os anos no mês de junho. $\mathrm{O}$ município recebeu o título de Capital Nacional do Boi-Bumbá pela Lei n ${ }^{\circ} 13.571$, de 21 de dezembro de 2017. Todos os anos, recebe turistas do Brasil e de vários países do mundo para assistir à disputa entre os Bois-Bumbás Garantido e Caprichoso na arena do Bumbódromo.

Garantido e Caprichoso são os dois principais Bois-Bumbás da cidade e do Amazonas. Apenas eles disputam o Festival Folclórico de Parintins. Os moradores da cidade de Parintins, bem como os de Manaus, dividem-se entre as torcidas de um e de outro Bumbá, que desenvolveram ao longo das décadas de sua existência uma intensa rivalidade.

O Boi-Bumbá Garantido é um boi branco que tem um coração vermelho na testa. Por isso, as cores vermelha e branca, além do coração, são seus símbolos. Seu fundador foi Lindolfo Marinho da Silva, mais conhecido como Lindolfo Monte Verde, descendente de brancos europeus e escravos negros (DÉMONTEVERDE, MONTEVERDE, 2003). Já o Boi-Bumbá Caprichoso é um boi preto que tem uma estrela azul na testa. Seus símbolos são, além da estrela, as cores azul e branca. Teria sido fundado pelos irmãos Raimundo Cid, Pedro Cid e Felix Cid, vindos do estado do Ceará (SAUNIER, 2003). Estima-se que ambos os bois tenham surgido nas primeiras décadas do século XX.

O Boi-Bumbá da cidade de Parintins mantém semelhanças, mas não se confunde com o Bumba-Meu-Boi do Maranhão. Certamente tem ali suas origens, quando principalmente cearenses e maranhenses chegaram a Parintins trazendo a cultura do Bumba-Meu-Boi durante o Ciclo da Borracha, ainda no século XIX. Ao longo do tempo, o Boi-Bumbá foi se distanciando do Bumba-Meu-Boi, sobretudo com o incremento de diversos aspectos e elementos culturais locais. Por exemplo, conforme (ASSAYAG, 1995), o negro começa a ceder lugar ao caboclo; o canto vai mudando e o verso vai substituindo termos africanos por termos indígenas; a mãe Catarina vira Catirina; Mateus perde o nome e fica sendo apenas o vaqueiro; Cazumbá e mãe Guiomã, figuras típicas da expressão negra, são esquecidas para o crescimento da filha do 
Patrão (sinhazinha da fazenda). E, finalmente, quem ressuscita o boi é o pajé e não mais o curador. Durante os anos, outras personagens foram inseridas nas apresentações, tais como a cunhã-poranga (a índia mais bonita da tribo). O auto do boi, ainda presente nas apresentações, faz-se acompanhar de rituais indígenas diversos.

Segundo Farias (2005), as toadas dos Bois-Bumbás são composições musicais feitas para a sua apresentação. Elas versam sobre o tema ou a homenagem escolhida pela agremiação folclórica para o Festival. As toadas retratam a apresentação e a evolução do boi, das alegorias, figuras típicas regionais e dos demais itens que se apresentam na arena do Bumbódromo. Conforme Rodrigues (2006), as toadas são a linha mestra daquilo que o boi vai levar para arena. São elas que direcionam como o boi vai evoluir na arena e como os artistas vão executar as alegorias. As letras das toadas expressam temas relacionados à cultura indígena e cabocla, à Amazônia, à religiosidade, aos itens das apresentações (pajé, cunhã-poranga, sinhazinha da fazenda, porta-estandarte, o próprio boi, etc.) e ao boi contrário (o rival), sendo estas últimas denominadas de toada de desafio; as letras empregam alguns regionalismos e diversos termos de línguas indígenas.

\section{Análise do discurso francesa}

Esta seção destina-se a expor os pressupostos teóricos Análise do discurso francesa (doravante $\mathrm{AD}$ ) que embasaram a análise do discurso aqui ensejada. Isso significa que muitos aspectos teóricos e históricos desse campo de estudos não são abordados, o que certamente representa uma lacuna, mas cuja solução demandaria um espaço não disponível e poderia conduzir à fuga dos objetivos acima expostos.

A AD francesa, cujo objeto é o discurso, é um campo heterogêneo de tendências de teorização sobre o discurso e de propostas metodológicas de análise (Cf. MAZIÈRE, 2007; MALDIDIER, 1994; AUTOR, 2020). Neste trabalho, segue-se a perspectiva e os conceitos da tendência de AD desenvolvida por Michel Pêcheux e seu grupo.

Nessa tendência, a teoria do discurso e seu método de análise são elaborados a partir da articulação (bem como da problematização) da perspectiva e dos conceitos do Materialismo Histórico, tal como concebido por Louis Althusser, da Linguística tal como definida por Ferdinand Saussure e desenvolvida pelos estruturalistas americanos, e da Psicanálise tal como desenvolvida por Jacques Lacan (Cf. PÊCHEUX; FUCHS, 1997). 
O discurso é definido, então, como uma das formas de existência material da ideologia, sendo um nível intermediário entre a língua e a fala, correspondendo a classes sociais em conflito umas com as outras. $\mathrm{O}$ discurso assim concebido tem como base material uma língua natural, isto é, todo discurso expressa-se em uma língua, e em uma mesma língua vários discursos, inclusive, contraditórios podem coexistir (Cf. PÊCHEUX; FUCHS, 1997; PÊCHEUX, 1988).

Além disso, o discurso não tem origem no sujeito que o reproduz em determinada conjuntura histórica, mas é produzido em formações discursivas que, por sua vez, são elementos de formações ideológicas de dada formação social (Cf. PÊCHEUX, 2011). O discurso, ao contrário de ser constituído pelo sujeito, é o que o constitui, na medida em que atua no processo de interpelação-assujeitamento, tal como teorizado por Althusser (1980). Consoante as palavras de Pêcheux (1988, p. 161): “[...] os indivíduos são 'interpelados’ em sujeitos-falantes (em sujeitos de seu discurso) pelas formações discursivas que representam 'na linguagem' as formações ideológicas que lhes são correspondentes".

Uma formação discursiva (FD), conforme Pêcheux (2011), elemento de uma formação ideológica, é aquilo que determina o que pode e deve ser dito a partir de uma posição ideológica em uma dada conjuntura, o que implica que determina também aquilo que não pode ser dito (o interditado dizer). Além disso, pode ser caracterizada como: a. um sítio de enunciados em relação de paráfrase e b. a matriz do sentido de palavras e expressões (significantes).

Decorre disso que os sentidos não são unívocos, mas podem ser múltiplos, já que dependem de uma dada FD onde são constituídos e associados aos significantes: “[...] as palavras 'mudam de sentido' ao passar de uma formação discursiva a outra" (HAROCHE; HENRY; PÊCHEUX, 2007, p. 26). "De fato, o sentido existe exclusivamente nas relações de metáfora (realizadas em efeitos de substituição, paráfrases, formações de sinônimos), das quais certa formação discursiva vem a ser historicamente o lugar mais ou menos provisório" (PÊCHEUX, 1988, p. 263).

Uma FD também se caracteriza por seus "temas" ou, ainda, objetos de discurso. Duas FDs podem se caracterizar pelos mesmos "temas", mas sob a modalidade da diferença (contradição de classe) ou por "temas” diferentes (Cf. PÊCHEUX; FUCHS, 1997; PÊCHEUX, 1990).

As FDs existentes em dada formação social, em dada conjuntura, não são independentes entre si, mas constituem-se a partir de relações diversas (de aliança, confronto, oposição, contradição, por um lado; e de dominação ou subordinação, por outro). O conjunto complexo de FDs é o que caracteriza o que Pêcheux (1988) chamou de interdiscurso. Assim, as FDs são 
definidas, delimitadas, ampliadas, reduzidas, transformadas, por seu exterior constitutivo, apesar de, por seus mecanismos constitutivos de funcionamento, apagarem a existência desse exterior (PÊCHEUX, 1988).

A AD francesa avançou na proposta de analisar discursos e FDs independentemente dos sujeitos que sustentam os discursos. Trata-se, assim, de uma proposta de análise não-subjetiva de discursos, isto é, não centrada das supostas intenções dos sujeitos. Os discursos, tendo seu funcionamento próprio, é que são objeto teórico-analítico.

\section{O discurso dos Bois-Bumbás Garantido e Caprichoso}

Nesta seção, analisa-se, conforme exposto anteriormente, o discurso dos Bois-Bumbás Garantido e Caprichoso acerca da Amazônia, tal como materializado nas letras de suas toadas.

A análise aqui apresentada perfez as seguintes etapas metodológicas. Primeiramente, foi estabelecido que a seleção do corpus seria por amostragem; dessa forma, foram selecionadas as toadas produzidas nos anos de 1995, 2000, 2005, 2010 e 2015, isto é, um espaço de 25 anos. Entende-se que esse recorte permite uma visão ampla dos discursos em análise ao longo desse espaço de tempo. Sendo assim, o corpus da pesquisa constitui-se de cerca de 200 letras de toadas.

Em seguida, foram selecionados das toadas os versos (sequências discursivas) que continham os termos pré-estabelecidos ("floresta", "mata", "selva", "natureza" e "Amazônia"). Havia versos desse tipo em 34 toadas, sendo 15 do Boi Garantido e 19 do Boi Caprichoso. Considerou-se, então, esse conjunto de significantes como uma das categorias temáticas do corpus (ao lado das outras encontradas), a categoria temática "floresta". Essa primeira análise dos versos conduziu à identificação de algumas "subcategorias temáticas", dado que há uma variação de temáticas sobre a floresta: Amazônia como floresta; exaltação da floresta; relações dos Bois-Bumbás com a floresta; defesa da preservação da floresta; denúncia da destruição da floresta. Considerando-se isso, as sequências discursivas foram reagrupadas de acordo com cada subcategoria. Esses gestos de interpretação foram necessários para uma melhor análise do material, bastante extenso. Destaca-se que as toadas de ambos os Bois-Bumbás apresentam as mesmas subcategorias temáticas. Isso permitiu a análise comparativa-contrastiva de seu(s) discurso(s) dos dois Bumbás.

Pode-se adiantar de saída que seus discursos sobre a floresta são homogêneos, isto é, não contraditórios entre si. Trata-se de um mesmo discurso regido por uma mesma FD. Podese comprovar isso com as seguintes constatações: a. a existência de um mesmo tema, a floresta; 
b. termos significantes "floresta", "Amazônia", "mata", etc. com único sentido; c. tema tratado de forma homogênea e não sob a modalidade da divisão. Todas são traços que individualizam uma FD, conforme exposto anteriormente. A rivalidade existente entre os Bumbás no festival de Parintins não se reproduz no seu discurso, havendo nesse nível, ao contrário, aliança.

\subsection{A Amazônia é a floresta}

No discurso dos bois-bumbás, os significantes "Amazônia", "floresta", "natureza" "mata", "selva" entretêm relações de substituição e/ou combinação. Portanto, no âmbito desse discurso, esses significantes são sinônimos: a Amazônia é a floresta (a selva, a mata). De outro ângulo, a floresta (a selva, a mata) é a Amazônia. Vejam-se os significantes destacados na sequência discursiva (SD) abaixo, onde estão em relação de substituição (Amazônia-mata):

SD1: Que a nossa Amazônia / Reluz no horizonte, onde floresce a vida/ Viagem de sonhos, caminho de brisal Que a mãe natureza teceu com carinho/ Fez brotar as cachoeiras tão cristalinas/ E um lindo arco-íris brilhar/ Pra contemplar a piracema semente divina/ Pra vida se proliferar/ E o cantar do Uirapuru disseminando na matal Seu lindo canto de paz. (Toada Nossa Amazônia - Boi Garantido, 2000)

Decorre disso que não se trata de termos designando referentes diversos: não se trata de qualquer floresta ou selva ou mata, mas da Amazônica. Outro elemento que ratifica nossa conclusão é a menção, na SD1 acima, ao pássaro uirapuru, um dos símbolos da Amazônia.

Vejam-se mais alguns exemplos:

SD2: O povo da selva reúne a grande nação/ E pede ao deus da floresta/ A sua proteção. (Toada Amazônia em prece - Boi Garantido 2010)

SD3: Coletores da Amazônia/ Que não matam o verde da selva/ Com sustentabilidade ensinam a viver/ Os povos da Amazônia. (Toada Coletores da Amazônia-Boi Garantido 2015)

O processo discursivo aqui descrito se caracteriza, assim, pelas relações de substituição/combinação, paráfrases e sinonímias entre esses significantes. Esse é o processo metafórico (de transferência) constitutivo do discurso em tela, isto é, o processo pelo qual um e mesmo sentido é atribuído a todos esses significantes.

Consequentemente, nesse discurso, a Amazônia é concebida como espaço geográfico constituído apenas por elementos naturais. Os elementos que dependem da ação humana (construídos), como os espaços urbanos, são apagados. Trata-se de um não-dito, do impossível dizer no interior dessa FD, a partir da posição ideológica que a rege. Mais adiante, quando tratarmos de outros aspectos desse discurso, como as relações dos Bumbás com a floresta, ficará 
mais claro o quanto o espaço natural é constitutivo desse discurso e da identidade dos BoisBumbás.

Em menor recorrência, há também efeito metafórico entre Amazônia e Amazonas. Os termos em substituição na SD4 abaixo remetem para uma fusão-identificação entre esses espaços. Assim, fortalece-se a ideia de espaço natural puro, exclusivo, reduzindo o estado do Amazonas a seus aspectos naturais.

SD4: Amazônia de mistérios, seus encantos/ Meu cantar/ Labirinto que envolve o pescador/Amazonas nosso amor/Minha estrela, meu lugar/Teu cenário embeleza meu Brasil. (Toada Amazonas nosso amor - Boi Caprichoso 2005)

A cidade de Parintins e o estado do Amazonas se localizam na Amazônia, certamente. Mas são espaços diluídos enquanto espaço específico, inclusive urbano, no espaço mais geral e natural da Amazônia.

A FD que rege o discurso dos dois Bois-Bumbás mantém relações de aliança com uma região do interdiscurso, que é o discurso do estrangeiro, que só vê a natureza da região, ou para quem interessa apenas a natureza, que é seu elemento característico e objeto de interesse. Esse discurso é frequentemente combatido no estado do Amazonas, que quer mostrar que também é urbano (não é só floresta), que também é teatro, cultura, indústria, prédios, etc. Na FD dos Bumbás, a FD da natureza-floresta e domina a FD da natureza-e-cultura.

Além disso, no discurso dos Bumbás de Parintins, a floresta é idealizada. O discurso que circula nos enunciados de Garantido e de Caprichoso é de engrandecimento da floresta, exaltação da natureza, vista como um lugar divino, belo, idealizado e com características poéticas. Pode-se notar isso nas SDs abaixo:

SD5: Mãe natureza/ inefável flor eterna/vem despertar/ que se abram os olhos da vida/ a voz que canta é a da florestal o trono verde espera o rei/ todos esperam o sol.../ na brisa mais leve, no doce beijo das manhãs / no grasnar do gavião, no rebojo da sucuriju/ águas cristalinas, corredeiras e cascatas/ o estrondar da cachoeira peristálical crisálidas pulsam, orquídeas afloram/ insetos que valsam ao som das cigarras. (Toada O Canto da Floresta - Boi Caprichoso 2010)

SD6: minha selva, rico e belo é o teu cenáriol imenso, colorido, teus braços, teus galhos/verde contemplário/ divino santuário/ minha selva recheada de sabor e sonhos/ corais em sinfonia de sublime encanto/ santo perfumado, teu manto/ teu sudário/ teu teatro lendário encantador/minha selva adornada de penas/de cantos selvagens/ pétala que arboresceu/ no teu céu a dança das plumagens/minha floresta de pele morena/ de límpidas águas, onde a vida repousa feliz/do saboroso buriti/ do abençoado curumim. (Toada Minha selva de cantos selvagens - Boi Caprichoso 2010)

SD7: Amazônia um legado em aquarela / Água terra fauna flora e cultural Obra-prima emoldurada de flores / Festa de luzes e cores / A brisa conduz o voo dos pássaros/ Compondo melodias naturais /Exóticos e raros orquidários / Abrigam os sonhos de paz/ Menina dos olhos do mundo. (Toada Aquarela da Amazônia - Boi Garantido 2005) 
A SD7 ratifica a FD da natureza dominante dos Bois de Parintins, em especial o verso Menina dos olhos do mundo, metáfora utilizada para simbolizar a beleza da floresta [Amazônica].

O discurso sobre o lado perigoso, feio ou assustador da floresta foi apagado, silenciado. Na FD em análise, é interditado dizer que a floresta também é o lugar onde vivem animais peçonhentos que causam sérios riscos à saúde, insetos incômodos que também podem causar doenças; que a densidade da mata dificulta a circulação de pessoas; cuja umidade aumenta a sensação de calor e o desconforto disso proveniente. Esse discurso que se sobressai, por exemplo, na obra Inferno Verde, de Alberto Rangel, é aqui silenciado, ignorado. Tudo em função da posição ideológica do que pode e deve ser dito e do que não pode e não deve ser dito.

A Amazônia é também o lugar onde acontece a festa do Boi-Bumbá. O discurso em análise localiza a festa do Boi-Bumbá como um evento que acontece na Amazônia, na floresta [Amazônica].

SD8: tem rufar de tambores/ que vem da florestal é da tribo Brasil, Amazônia/ nossa festa é folclore é bumba-meu-boi. (Toada Nossa festa de boi-Boi Caprichoso 2015)

SD9: E nesta grande festa da florestal Com o coração na testa o Garantido vai chegar.(Toada Pura emoção - Boi Garantido 2000)

Porém, historicamente, a disputa entre os dois Bumbás aconteceu em vários lugares da cidade de Parintins, como quadras, estádio de futebol até, finalmente, ganhar um local próprio, chamado de Bumbódromo, o qual foi construído especificamente para esta competição. Isso aparece nas toadas - a festa é em Parintins e seus espaços específicos (arena, campo, terreiro, curral, fazenda).

SD10: Venha pra cá ver meu povo cantando a toadal Mil bandeiras e fogos na quadra. (Toada Caprich'arteando - Boi Caprichoso, 1995)

SD11: Vem meu boi Caprichoso meu boi, meu boi-bumbál Balança bonito na arena. (Toada Boi de amar - Boi Caprichoso 2005)

SD12: Caprichoso é boi de festal É da cidade, é da campina. (Toada Boi de Santo - Boi Caprichoso 2005)

SD13: Parintins está em festal de azul vamos cantar. (Toada Tem folclore na florestaBoi Caprichoso 2015)

SD14: A arena vermelhou/ é palco rubro de paixão. (Toada Anunciação vermelha - Boi Garantido 2005)

SD15: Explode a magia vermelha na arquibancada. (Toada Todos os sentidos - Boi Garantido 2015) 
SD16: Na ilha, o boi mais querido é o boi Garantido. (Toada Boi de pândega-Boi Garantido 2015)

Assim, nesse aspecto do discurso, ao falar da festa do Boi, o espaço urbano retorna e é valorizado, destacado. As sequências com os termos campo, curral, terreiro, fazenda remetem aos antigos lugares onde os bois se apresentavam, fazendo isso parte do discurso da valorização da tradição (atualmente é no bumbódromo, lexicalizado como arena). Aqui há uma contradição interna dessa FD (festa na floresta e na cidade, espaço urbano). O interditado, o recalcado retorna mostrando que a Amazônia não é só floresta, mas cidade, espaço construído. A região do interdiscurso lá apagada, aqui emerge.

Mas ao examinarmos o corpus e cotejarmos com a identificação entre Amazônia e floresta, percebemos que a Amazônia em seu aspecto urbano, construído pelo homem, é enfraquecido no discurso dos Bumbás. A Amazônia ganhou um lugar de destaque, concebida como floresta, natureza, selva e mata. Logo, a ênfase recai sobre a festa que acontece na floresta como espaço natural, puro, belo e harmônico, e não no espaço urbano.

\subsection{A Amazônia - "casa e guarida"}

No discurso em análise, a floresta é não apenas o lugar de origem dos Bois-Bumbás ou o lugar onde acontece a festa do Boi-Bumbá, mas é sobretudo a sua condição de existência, na medida em que eles não apenas dependem dela, mas são parte dela. Vejam-se as seguintes SDs:

SD17: Nossa Amazônia que é o nosso lar/Ar que eu respiro e que me faz cantar. (Toada Nossa Amazônia - Boi Garantido 2000)

SD18: Eu sou esse rio, esse sol, essa terra/ Sou parte da selva, ela é parte de nós. (Toada Rios de promessa - Boi Caprichoso 1995)

SD19: Garantido é uma belezal É fruto da natureza (Toada Minha riqueza - Boi Garantido 1995)

SD20: Amazônia te venero / Amazônia eu te quero/ Pra viver até morrer / Amazônia minha vidal Minha casa e guarida. (Toada Amazônia em prece - Boi Garantido 2010)

SD21: Em cada tambor, em cada toada / em versos de amor, vem cantar / somos todos caboclos, somos entes da selva. (Toada O Canto da Floresta - Boi Caprichoso)

No discurso em análise, a Amazônia é "casa e guarida" não apenas dos Bois-Bumbás, mas também dos povos da floresta - os indígenas, seus habitantes originários, e os caboclos e demais mestiços que habitam hoje a região por força de eventos históricos, tais como o Ciclo da Borracha. Observe-se a SD abaixo: 
SD22: minha floresta de pele morena/ de límpidas águas, onde a vida repousa feliz/ do saboroso buriti/ do abençoado curumim. (Toada Minha selva de cantos selvagens - Boi Caprichoso 2010)

Nela, a Amazônia, lugar rico em biodiversidade, pertence à população que nela vive: "floresta de pele morena" e "abençoado curumim" destacam a herança indígena, recuperando a memória dos povos originários. Os povos originários da floresta encontram nela uma vida feliz, com alimento ("buriti”) e outras condições de existência ("límpidas águas").

O uso do pronome possessivo "nossa" na SD23: Que a nossa Amazônia / Reluz no horizonte, onde floresce a vida. (Toada Nossa Amazônia - Boi Garantido, 2000) corrobora o que foi dito.

A floresta como aquela que fornece o alimento se reproduz também nesta SD24: $O$ caboclo caniça a esperança/ Nas águas dos rios. (Toada Rios de promessa - Boi Caprichoso 1995). O caniço é uma espécie de vara de pescar do caboclo, com a qual ele retira dos rios o peixe, o item mais importante de sua alimentação. $\mathrm{O}$ alimento é a esperança de vida.

A floresta também fornece substâncias que podem curar as doenças, as ervas medicinais.

SD23: A cura de todas as dores/ E todos os males está na florestal O caboclo em harmonia com a naturezal Se embrenha na mata em busca de ervas medicinais/ Consciência ecológica/ Dos povos da Amazônia / Copaíba, andiroba, sucuba/ Unha de gato, carapanaúbal Miraruira e leite de Amapál (Toada Sabedoria cabocla - Boi Garantido 2005)

Assim, também quanto a este aspecto, o discurso dois Bois-Bumbás é homogêneo, não havendo contradição que caracterizaria duas FDs em oposição.

\subsection{A Amazônia - identidade constitutiva dos Bois-Bumbás}

Em outras SDs, nota-se mais fortemente os Bois como elementos da natureza.

SD24: É vermelho o amanhecer/ É vermelho o entardecer/ Meu coração é vermelho/ Tudo que é lindo é vermelho/ Vou te mostrar onde mora/ Onde mora o amor/ [...] É na fazenda mais bonita e verdejante/ Entre as flores coloridas de um jardim/ É perfeito onde mora o Garantido/ Onde a brisa é perfumada de jasmim. (Toada Xô urubu - Boi Garantido 2005)

Os elementos da natureza, como o sol, a lua, o céu, o sereno, dentre outros, são recorrentes em várias toadas do Boi Garantido. O Boi branco é o elo, é a conexão positiva entre a natureza e o festival de Parintins: tem a lua como par, é radiante como o raio de sol, traz felicidade por onde passa, sua cor simboliza a paz e a pureza.

SD25: Garantido meu raio de sol/ Claridade cintilante de um ser/ De rara beleza/ Reluz e faz apaixonar/ Ao primeiro olhar/ O céu ostenta um véu bordado de estrelas/ E o 
Garantido tem a lua como par/ Da cor da paz traduz assim sua pureza/ Resplandecente/ Seduz a gentel Evoluindo e serenando ao luar. (Toada Evolução vermelha - Boi Garantido 2000)

De maneira similar, nas toadas do Boi Caprichoso também há SDs tematizando o BoiBumbá como elemento da natureza, com destaque para o sol, o céu (devido à sua cor azul) e as estrelas (a estrela é um de seus símbolos, como dito anteriormente).

SD26: Como a brisa das manhãs/desnudando a madrugada/ [...] meu canto se fez azul/ e me faz cantar assim [...]/ Meu amor é azul, azul, azul/ azul que vem do brilho das estrelas/ azul da cor do céu, do firmamentol este azul que não me sai do pensamento. (Toada Meu amor é azul - Boi Caprichoso 2010)

Diante disso, conclui-se que os discursos dos dois Bois-Bumbás em relação à natureza são homogêneos, havendo diferenças apenas nos aspectos simbólicos dos elementos da natureza (o vermelho do entardecer, a lua, o raio de sol / o branco das manhãs, o azul de céu, as estrelas).

Garantido e Caprichoso estão em harmonia com a floresta, seu lugar e origem, e têm com ela uma ligação constitutiva (da floresta depende sua existência), uma vez que são partes dela. A floresta é constitutiva da identidade e da existência dos dois Bois-Bumbás.

\subsection{A defesa da preservação da Amazônia}

Tanto Garantido quanto Caprichoso sustentam o discurso da defesa da preservação da floresta [Amazônica]. As toadas são as vozes de clamor pela vida, que está interligada à floresta, depende dela. Considerem-se as SDs a seguir:

SD27: Divina força, luz intensa que move o mundo/ [...] fez a terra e o homem/ a natureza para amar/ reinventar e preservar, ter orgulho, admirar Amazônia. (Toada Amazônia, arte da criação - Boi Caprichoso 2015)

SD28: Menina dos olhos do mundo Onde a vida clama preservação [...] O nosso amor é a Amazônia/ Dos sonhos de Chico Mendes/ Em defesa do ambientel O nosso amor é a Amazônia/ Exaltada nas toadas/ Na festa do boi Garantido. (Toada Aquarela da Amazônia - Boi Garantido 2005)

Na SD30 acima, a Amazônia, menina dos olhos do mundo, é o amor dos povos da floresta e dos Bois-Bumbás. Devido a sua importância precisa ser preservada. Nessa mesma $\mathrm{SD}$, recupera-se a memória de Chico Mendes, seringueiro, ativista e ambientalista cujo "sonho" era preservar a Amazônia da destruição, em posição aos interesses dos grandes fazendeiros.

Na materialidade linguística do discurso dos Bois-Bumbás a oração imperativa negativa é recorrente, como nas SDs a seguir: 
SD29: Não desmate, não maltrate Não polua, não destrua/ Que a natureza mãe é vida. (Toada Sabedoria cabocla - Boi Garantido 2005)

SD30: 10 Eu vou, eu vou brincar de boi, / No meio dessa floresta / Não deixe morrer o meu verde / Não deixe acabar minha festa. (Toada Luz de esperança - Boi Caprichoso 1995)

SD31: E nada de matar o verde, só paz na floresta/ Vamos brincar no Caprichoso e mostrar nessa festal Que a Amazônia é rica e bela e precisa viver. (Toada Amazonas nosso amor - Boi Caprichoso 2005)

Há, portanto, ao lado do apelo ou da ordem uma proposta: brincar de boi e, brincando, defender a preservação da floresta. Como dito anteriormente, a preservação da Amazônia é necessária porque ela é a condição da existência do próprio Boi-Bumbá.

\subsection{A denúncia da destruição da Amazônia}

Desde o início da colonização, a floresta é destruída. Antes, pelo branco europeu. Agora, pelo grileiro, o minerador, o agropecuarista, dentre outros. Todos a destroem para retirar suas riquezas. Esses fatos históricos são referidos na SD abaixo:

SD32: Devastaram o meu verdel Não deixaram uma planta no chão/Fauna e flora destruídas/Pela mente corrompida/ Maltratando o meu chão/Mãe Natureza/ Faz sorrir uma criançal És a luz da esperança/ É a flor do amanhã. (Toada Luz de esperançaBoi Caprichoso 1995)

O discurso de ambos os Bumbás denuncia a prática da destruição iniciada no passado e continuada no presente, e a opõe à prática da preservação operada pelos povos originários:

SD33: Eu sou um índio/ Sou um índio guerreiro/ Sou também feiticeiro/ Mas eu não quero guerral Quero a paz na terral A selva pra caçar/ E o rio pra pescar/ Eu sou um indio/ Pense nisso seu branco/ Já tiraste o encanto/ O esplendor da florestal Quase nada me resta/ Eu só quero viver/Ver meu filho crescer/Me deixe em paz seu moço/ Ou eu fico louco/ Respeite os limites pra manter minha naçãol Não preciso do seu saber/ Porque isso me faz sofrer/ Eu já tenho a beleza/ Da mãe natureza pra sobreviver. (Toada Índio - Boi Garantido 1995)

É recorrente no discurso dos Bumbás a assunção da perspectiva do indígena e do caboclo, o que é marcado pelo emprego do pronome pessoal "eu".

O verso Não preciso do seu saber recupera o discurso segundo o qual os indígenas não precisam da cultura do homem branco, uma vez que eles já possuem a sua própria cultura. Ativa a memória de discursos dominantes no passado acerca do indígena como povo sem cultura (ou não-civilizado ou inferior), o discurso do colonizador europeu, que atualmente é abertamente combatido por um outro discurso, o do indígena como povo desenvolvido culturalmente. Ativa também os conflitos que marcaram a relação entre colonizador e indígena no passado e que 
marca ainda hoje a relação entre indígenas e não indígenas interessados nas riquezas de suas terras. Ativa ainda o discurso do índio como povo guerreiro, mas que prefere praticar a paz e viver em seu lugar de fato e de direito. Os versos finais, no entanto, são quase uma ameaça: $M e$ deixe em paz seu moço/ Ou eu fico louco. O verbo no imperativo Respeite os limites pra manter minha nação não significa um pedido, mas sim uma ordem, um mecanismo de preservar a sua etnia.

As sequências discursivas citadas proferem críticas ao passado, ao processo de colonização na Amazônia. Podemos parafrasear o seguinte: houve desmatamento, devastação do verde, mas não houve reflorestamento. Contudo, há uma esperança que é a metáfora: a natureza é a luz da esperança, é a flor do amanhã. Há o discurso da valorização do verde (presente na memória do passado e do presente), com destaque ao verso Devastaram o meu verde que foi dito em SDs anteriores.

No discurso de Garantido e Caprichoso há uma apropriação das lendas amazônicas e criaturas míticas para fortalecer a defesa e a preservação. Por exemplo, a lenda do Curupira, ser mítico da floresta que afugenta os caçadores que ameaçam a floresta, e a do Mapinguari, um gigante peludo com um olho na testa e uma boca no umbigo, também defensor da floresta.

Dessa maneira, os Bois-Bumbás Garantido e Caprichoso, assim como o Curupira, o Mapinguari e outras criaturas lendárias, representam os defensores da floresta e lutam pela união de todos os povos pela preservação da floresta, conforme os versos abaixo:

SD34: Oh nossa deusa mãe, oh nossa deusa mãe/ Silenciai o ronco das motosserras / E protegei os seres vivos da florestal Mãe Natureza enviai salvação/ Eis o vosso lendário guardião!/ Avante Mapinguari, avante Mapinguari (2x)/ Animal colossal, fera sobrenatural/ O abraço mortal de sucuriju/A boca voraz de jacaré-açu/ O olho que tudo vê, o olho que tudo vêl Aos agressores da naturezal Hipnose, devaneio e pesadelol Decifra-me ou vou te devorar. (Toada O enigma do Mapinguari - Boi Garantido 2010)

Garantido e Caprichoso se unem aos povos e seres da floresta em prol da preservação da Amazônia, que é fonte de vida. Também dessa perspectiva, há uma única FD regendo os discursos dos Bumbás.

\section{Considerações finais}

No presente artigo foi feita a análise do discurso dos Bois-Bumbás Garantido e Caprichoso, especificamente, um recorte da pesquisa na representação da floresta. Os resultados indicaram que existe uma relação de confronto entre eles somente no aspecto da disputa pelo título de campeão do Festival Folclórico de Parintins. 
No plano discursivo-ideológico, os dois Bumbás são regidos por uma mesma formação discursiva. Assim, os dois Bumbás não sustentam discursos contraditórios entre si, com relações de dominação-subordinação, a partir de posições ideológicas distintas. Pelo contrário, são de aliança. Mesmo apresentando vários temas acerca da Floresta Amazônica, observamos que os discursos que circulam são homogêneos. Tanto Garantido quanto Caprichoso exaltam a floresta, possuem uma relação de união e dependência com a natureza, valorizam a cultura indígena, o modo de viver do caboclo, denunciam a destruição da floresta e os massacres de povos indígenas ocorridos no passado, lutam pela sustentabilidade em relação ao meio ambiente, em enunciados que estão em relação de paráfrases e metáforas.

\section{REFERÊNCIAS}

ALTHUSSER, Louis. Aparelhos Ideológicos de Estado. Posições 2. Rio de Janeiro: Graal, 1980, p.47-101.

ASSAYAG, Simão. Boi-Bumbá. Festas, andanças, luz e pajelanças. Rio de Janeiro;

Minc/Funarte, 1995.

BOI CAPRICHOSO. Disponível em:< http://boicaprichoso.com/toadas.asp $>$. Acesso em 15 abril de 2018.

BOI GARANTIDO. Disponível em: 〈https://www.letras.mus.br/garantido/>. Acesso em 20 de mai. de 2018.

DÉMONTEVERDE; MONTEVERDE, João Batista. Boi Garantido de Lindolfo. Manaus: Editora da Universidade do Amazonas, 2003.

FARIAS, Júlio César. De Parintins para o mundo ouvir. Na cadência das toadas dos boisbumbás Caprichoso e Garantido. Rio de Janeiro: Litteris Ed., 2005.

HAROCHE, Claudine; HENRY, Paul; PÊCHEUX, Michel. A Semântica e o corte saussuriano: língua, linguagem, discurso. In: BARONAS, R. L. (Org). Análise do discurso: apontamentos para uma história da noção-conceito de formação discursiva. São Carlos: Pedro e João, 2007, p. 13-32.

MALDIDIER, Denise. Elementos para uma história da análise do discurso na França. In:

ORLANDI, Eni (Org). Gestos de leitura: da história no discurso. Campinas: Ed. da Unicamp, 1994. p. 15-28.

MAZIÈRE, Francine. A análise do discurso: história e práticas. São Paulo: Parábola, 2007. AUTOR, 2020.

PÊCHEUX, Michel. Língua, linguagens, discurso. In: PIOVEZANI, Carlos; SARGENTINI, Vanice. (Orgs.). Legados de Michel Pêcheux: inéditos em análise do discurso. São Paulo: Contexto, 2011.p. 63-76.

. Remontons de Foucault à Spinoza. In: MALDIDIER, Denise (Org.). L'Inquiétude du Discours. Paris: Cendres, 1990. p. 245-260. 1988. . Semântica e discurso: uma crítica à afirmação do óbvio. Campinas: Ed. da Unicamp,

; FUCHS, Catherine. A propósito da Análise Automática do Discurso: atualização e perspectivas. In: GADET, Françoise; HAK, Tony (orgs.). Por uma análise automática do 
discurso: uma introdução à obra de Michel Pêcheux. 2. ed. Campinas: Editora da Unicamp, 1997. p. 163-252.

RANGEL, Alberto. Inferno Verde: Cenas e Cenários do Amazonas. $6^{a}$ ed. revisada. Manaus: Editora Valer, 2008. (Memórias da Amazônia).

RODRIGUES, Allan Barreto. Boi-Bumbá: Evolução. Livro reportagem sobre o Festival Folclórico de Parintins. Manaus: Editora Valer, 2006.

SAUNIER, Tonzinho. Parintins: memórias dos acontecimentos históricos. Manaus: Editora Valer/Governo do Estado do Amazonas, 2003.

Recebido em 12/06/2020. Aceito em 19/09/2020. 